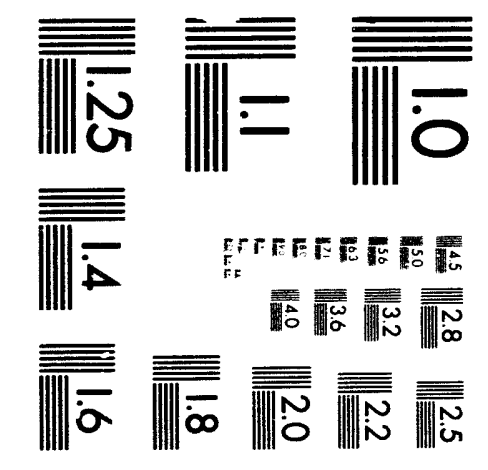



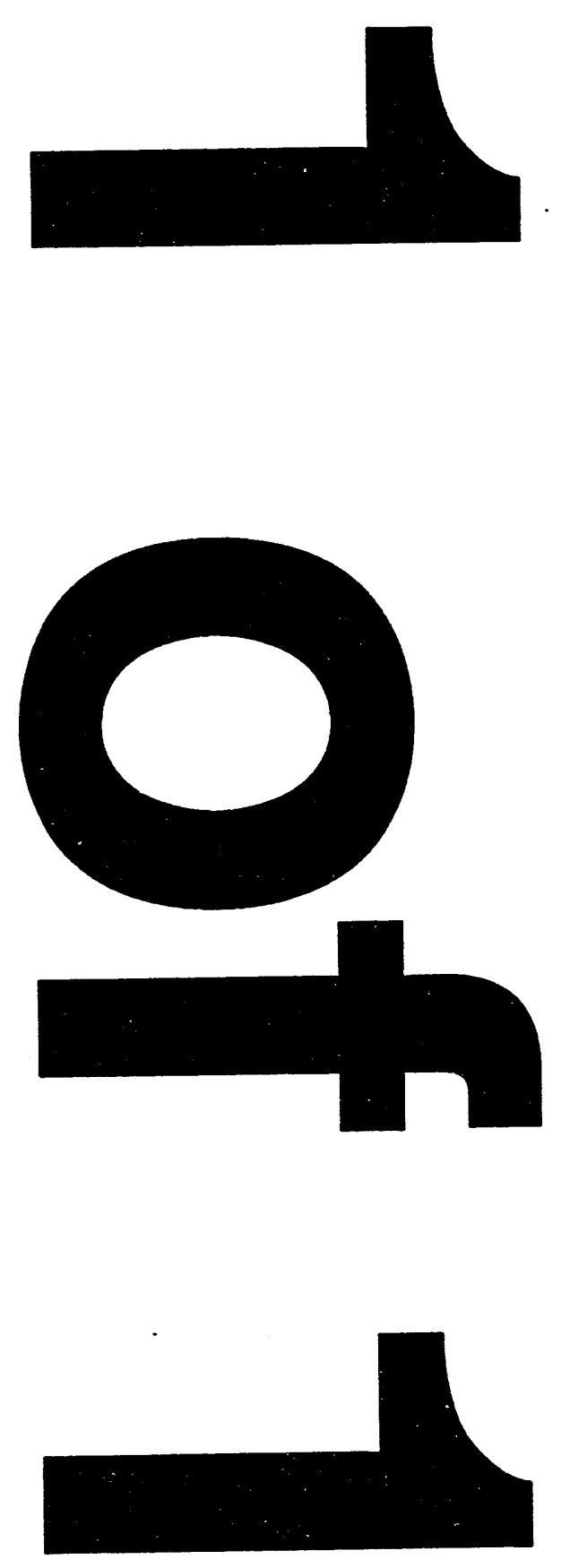
WAPD $-T-2949$

\title{
ANALYSIS OF BENCHMARK CRITICAL EXPERIMENTS WITH ENDF/B-VI DATA SETS
}

\author{
J. Hardy, Jr. and A. C. Kahler \\ Westinghouse Electric Corporation \\ Bettis Atomic Power Laboratory \\ P.O. Box 79 \\ West Mifflin PA 15122 \\ (412) $476-5975$
}

\author{
To Be Submitted to \\ American Nuclear Society \\ International Topical Meeting \\ Advances in Mathematics, Computations, and Reactor Physics \\ Pittsburgh PA \\ April 1991
}

\section{DISCLAIMER}

This report was prepared as an account of work sponsored by an agency of the United States Government. Neither the United States Government nor any agency thereof, nor any of their employees, makes any warranty, express or implied, or assumes any legal liability or responsibility for the accuracy, completeness, or usefulness of any information, apparatus, product, or process disclosed, or represents that its use would not infringe privately owned rights. Referprocess disclosed, or represents that to any specific commercial product, process, or service by trade name, trademark, manufacturer, or otherwise does not necessarily constitute or imply its endorsement, recommanufacturer, or otherwise does not neces States Government or any agency thereof. The views and opinions of authors expressed herein do not necessarily state or reflect those of the United States Government or any agency thereof. 


\title{
ANALYSIS OF BENCHMARK CRITICAL EXPERIMENTS WITH ENDF/B-VI DATA SETS* \\ J. Hardy, Jr. and A. C. Kahler Westinghouse Electric Corporation Bett is Atomic Power Laboratory West Mifflin, Pennsylvania
}

\begin{abstract}
Several clean critical experiments were analyzed with ENDF/B-VI data to assess the adequacy of the data for $U^{235}, U_{238}$ and oxygen. These experiments were 1) a set of homogeneous $\mathrm{U}_{235}-\mathrm{H}_{2} \mathrm{O}$ assemblies spanning a wide range of hydrogen/ uranium ratio, and 2) TRX-1, a simple, $\mathrm{H}_{2} \mathrm{O}$-moderated Bettis lattice of slightly-enriched uranium metal rods. The analyses used the Monte Carlo program RCPO1, with explicit three-dimensional geometry and detailed representation of cross sections. For the homogeneous criticals, calculated $k$ crit values for large, thermal assemblies show good agreement with experiment. This supports the evaluated thermal criticality parameters for U235. However, for assemblies with smaller $H / U$ ratios, $k$ crit values increase significantiy with increasing leakage and flux-spectrum hardness. These trends suggest that leakage is underpredicted and that the resonance eta of the ENDF/B-VI U235 is too large. For TRX-1, reasonably good agreement is found with measured lattice parameters (reaction-rate ratios). Of primary interest is rho28, the ratio of above-thermal to therma 1 U238 capture. Calculated rho28 is 2.3 $( \pm 1.7) \%$ above measurement, suggesting that $U 238$ resonance capture remains slight ly overpredicted with ENDF/B-VI. However, agreement is better than observed witil earlier versions of ENDF/B.
\end{abstract}

\section{INTRODUCTION}

To upgrade cross section data, two types of benchmark critical experiments have been analyzed with cross sections from Version VI of the Evaluated Nuclear Data File (ENDF/B-VI): 1) a set of homogeneous $\mathrm{U}_{2} 35-\mathrm{H}_{2} \mathrm{O}$ assemblies, and 2) TRX-1, an $\mathrm{H}_{2} \mathrm{O}$-moderated Bettis lattice of aluminum-Clad, slightlyenriched uranium rods. In the analyses, which employed the RCPO1 Monte Carlo program!, the assemblies were modeled explicitly in three-dimensioris, and cross sections were represented in fine detail. The purpose of this work was to assess the adequacy of the ENDF/B-VI data evaluations for U235 (including the fission spectrum), $U 238$, and oxygen.

*Work supported by Department of Energy Contract DE-AC11-88PN38014. 
Detailed elastic scattering, capture and (when appropriate) fission cross section profiles were constructed from $0.0005 \mathrm{eV}$ to $21.17 \mathrm{MeV}$ using a Bettis processing program which contains elements of the NJOY2 and RCPL1 3 computer codes. For each nuclide, energy mesh generation (and subsequent thinning) followed the default guidelines for the NJOY program and resulted in a variable energy mesh with cross sections that were (generally) linearly interpolable to an accuracy within 1\%. Subsequently, the profiles for all nuclides in the cruss section library were interpolated onto a common energy mesh, containing in excess of 40000 energy points, for use by RCPO1.

Elastic scattering angular distributions and inelastic cross sections were collapsed into a group structure. This structure contains 28 groups from 5.5 $\mathrm{keV}$ to $21.17 \mathrm{MeV}$. The elastic center-of-mass angular distributions were approximated by a group-averaged $P_{3}$ Legendre expansion. Below $5.5 \mathrm{keV}$, elastic scattering is assumed isotropic. The group-averaged inelastic cross sections and group-to-group transfer probabilities were calculated from the appropriate cross-section and secondary-energy-distribution data in the ENDF/B file.

\section{ANALYSIS OF HOMOGENEOUS U235- $\mathrm{H}_{2} \mathrm{O}$ ASSEMBLIES}

Homogeneous critical assemblies have been used extensively in the past to test cross section data for $\mathrm{U}_{235}$ and $\mathrm{H}_{2} \mathrm{O}$. The following experiments were chosen for the present study:

1) Four Gwin-Magnuson assemblies - relatively dilute aqueous solutions of uranyl nitrate in large spherical and cylindrical aluminum containers, unreflected".

2) Six small Oak Ridge assemblies 5,6 with lower $H / U$ ratios (designated L5 L10) - uranyl fluoride solutions in cylindrical and spherical aluminum containers, mostly unreflected (but some reflected with $\mathrm{H}_{2} \mathrm{O}$ ).

3) Seven Rocky flats experiments - uranyl nitrate solutions in cylindrical aluminum containers, unreflected. These supplement the small ORNL assemblies. They appear to have been run with painstaking attention to detail, and are thoroughly documented?.

In the Monte Carlo analyses, the assemblies were described explicitly in three dimensions, in most cases including the vessel. However, some assemblies are specified without the container and have correspondingly small experimentallydetermined $k_{c r i t}$ corrections. The models for the Rocky flats assemblies included the container and a portion of the filling pipe.

The Monte Carlo analyses were run on the Bettis Cray YMP computer and were highly converged. There were usually at least four independent calculations of one million histories each. Final kcrit uncertainties were typically around $0.1 \%$ or less (95\% confidence interval). 
Most of these calculations were done with preliminary ENDF/B-VI data sets, as indicated in Table 1. Subsequently, the U235 evaluation (MAT 9228) was modified, and a new oxygen evaluation (MAT 825) was adopted for the final ENDF/B-VI. In addition, the U235 fission spectrum was a Bettis evaluation that is very close to ENDF/B-VI. In all cases, however, comparisons were subsequently made with final ENDF/B-VI data to evaluate the differences.

At the large-H/U limit (highly thermalized, low-leakage assemblies), calculated $k$ crit values are primarily sensitive to the thermal criticality parameters of $\mathrm{J}_{25}$. Inclusion of assemblies with lower $H / U$ introduces sensitivity to above-thermal leakage and above-thermal U235 fission rate (flux spectrum hardness).

Calculated $K_{\text {crit }}$ results are shown in Table 2 along with values of fast leakage and above-thermal U235 fission rate.

The results of a least-squares (LS) fit in terms of these variables are shown in Figures 1 and 2 . These figures display separately the leakage and fluxspectrum-hardness components of the observed $k$ crit trend, as determined in the least-squares fit. Specifically, the $k_{\text {crit }}$ for the ith assembly can be written:

$$
k_{i}=A+B \times L+C \times F_{25}+d k_{i}
$$

where

$$
\begin{aligned}
L & =\text { fast leakage } \\
F_{25} & =\text { above-thermal fission } \\
k_{i} & =\text { calculated } k_{\text {crit }} \text { for assembly } i \\
d k_{i} & =\text { difference of } k_{i} \text { from the LS-fit prediction }
\end{aligned}
$$

and $A, B$ and $C$ are parameters determined in the LS fit.

The "projected kcrit" is

$$
\begin{aligned}
\operatorname{projk}_{i} & =k_{i}-\operatorname{CXF}_{25} & & \text { (vs fast leakage) } \\
& =k_{i}-B \times L & & \text { (vs above thermal fission) }
\end{aligned}
$$

in Figures 1 and 2 respectively. (The number beside a plotted point identifies the particular assembly, for example, Gwin-Magnuson assembly ORNL10).

The ENDF/B-VI data, primarily the thermal criticality parameters of U235 (preliminary Mat 9228 ), give a good $k_{c r}$ it value at the dilute, highly-thermal limit (0.9993 for ORNL10). A modified version of Mat 9228, having a drooping eta below $0.0253 \mathrm{eV}$, also was found to give a good $k_{\text {crit }}(0.9982$ for ORNL10). The modified version was adopted for ENDF/B-VI.

The effect of using the ENDF/B-VI fission spectrum for U235 appears to be smal1. For assembly 17 , which has the most leakage, use of the ENDF/B-VI spectrum increased $k_{c r i t}$ by $0.0012 \pm 0.0013$. 
The $k_{c r i t}$ values in Figure 1 show a systematic increase with above-thermal leakage. Part of this trend (perhaps 0.003 at the high leakage end) is due to the multigroup elastic scattering angular representation in RCPO1, which can be improved with new coding. In addition, there are two major data sensitivities: the $U^{235}$ fission spectrum (mean energy and shape), and the oxygen high energy scattering cross sections and angular distributions. The oxygen data set for these calculations is ENDF/8-V, Mat 1276. Subsequentiy, kerjt results were obtained with Mat 825, the oxygen evaluation adopted for ENDF/B-VI. These yielded a net decrease of $0.0030 \pm 0.0014 \Delta k$ for L7 compared to ORNL10, indicating that deficiencies in the Mat 1276 oxygen evaluation are a significant contributor to this trend.

The $k$ crit values in Figure $2 a$ show a systematic increase with above-thermal U235 fission rate (flux spectrum hardness). The major data sensitivity here is the resonance alpha (capture/fission ratio) of U235, which is 0.477 for Mat 9228. As an illustration of this sensitivity, an alternate data set with U235 resonance alpha of 0.512 exhibits negligible slope versus above-thermal fission rate. These results are displayed in Figure $2 b$.

Before attempting to draw some conclusions from Figures 1 and 2 , it is necessary to try to form some idea of the uncertainties of $k$ crjt stemming from uncertainties of the materials content and dimensions of the critical assemblies. While it is difficult to reach any quantitative judgment on this question, some observations are pertinent:

- In the LS fit, the overall residual scatter of individual $k_{\text {crit }}$ values is approximately 0.0025 (standard deviation).

- The limiting $k$ crit at the low-leakage, soft-spectrum end (based on the mean of all the large Gwin-Magnuson assemblies) is thought to be well known.

- The Rocky flats assemblies are well documented and appear to have been run with painstaking attention to detail. They show good agreement with the ORNL assemblies.

The leakage trend (Figure 1), which involves the limiting $k_{c r j t}$ on one end and all the Rocky Flats assemblies at the other, appears to be welf established.

The spectrum-hardness trend (Figure 2) depends strongly on two of the small assemblies: ORNL L5 and L6. Several sensitivity calculations were made for these assemblies, with results shown in Table 4 . The primary sensitivity is to overall solution density. Although there is some question as to its precision, the specific gravity appears to be well determined 6 : quoted values are 2.013 for the $H / U=27.1$ solution and 1.661 for the $H / U=44.3$ solution (used in $L 5$ and $L 6$ respectively). In comparison, the precision of specific gravity determinations for the Rocky Flats assemblies is $0.06 \%$ on average.

A reasonable overall uncertainty on $k_{\text {crit }}$ for individual assemblies is judged to be .003 (standard deviation). 


\section{ANALYSIS OF TRX-1 CRITICAL EXPERIMENTS}

The TRX-1 critical assembly was a simple $\mathrm{H}_{2}$ O-moderated and reflected lattice of slightly-enriched uranium metal rods clad in aluminum. Among the experiments carried out in this assembly were measurements of lattice parameters (i.e., reaction-rate ratios) such as rho28, the ratio of above-thermal to thermal $U^{238}$ capture $^{8}$. TRX-1 is one of the thermal reactor benchmarks of the Cross Section Evaluation Working Group9. A full-core model of TRX-1 was used previously to calculate measured lattice parameters with ENDF/B-IV data:o. The calculation used the RCPO1 Monte Carlo program, and described cross sections and the lattice geometry in explicit detail. As part of the CSEWG data testing effort, the old ENDF/B-IV calculation has been repeated with ENDF/B-VI data as shown in Table 1, including MAT 9237 for U:38.

Calculated lattice parameters are summarized in Table 4. These are obtained from reaction rates edited for the central, asymptotic portion of the lattice. These are (with a thermal-cut energy of $0.625 \mathrm{eV}$ ):

$$
\begin{aligned}
& \text { Rho28 = Above-thermal U238 capture/Thermal U238 capture } \\
& \text { De1ta25 = Above-thermal Uazs fission/Thermal U235 fission } \\
& \text { Delta28 = U238 fission/U235 fission }
\end{aligned}
$$

There is generally good agreement with experiment, within the uncertainties, although calculated rho28 is slightly high and $k_{c r i t}$ low.

In a second RCPO1 calculation, the ENDF/B-VI U238 was replaced with Version $V$ (MAT 1398). The value of rho28 changed to $1.373 \pm 0.006$ and $k$ crit to $0.9940 \pm 0.0008$. This shows explicitly the effects of the difference in U238 evaluations. One of the major differences is extension of the resolved resonance range up to $10 \mathrm{keV}$ in Version VI, from $4 \mathrm{keV}$ in the earlier versions.

There has been a long-standing problem that ENDF/B U238 data overpredicted resonance capture in $U z 3 \mathrm{e}$ and consequently produced low $k$ crit values and high conversion ratios:1. This is illustrated for TRX-1 in Figure 3, which shows the RCPO1 results obtained with ENDF/B-IV and ENDF/B-VI. Also shown is a calculation with ENDF/B-V data performed by $P$. F. Rose and E. Schmidt at Brookhaven National Laboratory with the SAM-CE Monte Carlo Program:1. In addition, the RCPO1 point with Version $V U 238$ is shown (labeled "ENDF/B-V"). Although rho28 is still slightly high, and $k$ crit low, Version VI provides improved agreement with experiment relative to the earlier versions. 


\section{CONCLUSIONS}

In summary, these studies of ENDF/B-VI data sets indicate that:

1) The U235 thermal criticality parameters perform well.

2) There is a residual trend of $k_{\text {crit }}$ with above-thermal leakage, but use of Mat 825 (ENDF/B-VI oxygen) in place of Mat 1276 (ENDF/B-V oxygen) significantly reduces this trend.

3) There is a strong trend of $k_{c r}$ it with above-thermal fission rate. This suggests that the resonance alpha of ENDF/B-VI U235 (Mat 9228) is too low.

4) For TRX-1, calculated lattice parameters are in reasonably good agreement with experiment. Of primary interest, rho28 calculated with ENDF/B-VI Mat 237 is $2.3( \pm 1.7) \%$ above measurement. This is better agreement than was found with earlier versions of ENDF/B. 


\section{REFERENCES}

1. N. R. Candelore, R. C. Gast and L. A. Ondis II, RCPOI - A Monte Carlo Program for Solving Neutron and Photon Transport Problems in Three-Dimensional Geometry with Detailed Energy Description, WAPD-TM-1267, August 1978.

2. R. E. Macfarlane, D. W. Muir, and R. M. Boicourt, "The NJOY Nuclear Processing System, Volume 11: The NJOY, RECONR, BROADR, HEATR and THERMR Modules", LA-9303-M, Vol.11 (ENDF-324) (1982).

3. A. V. Oralle, N. R. Canaelore and R. C. Gast, "RCPLl - A Program to Prepare Neutron and Photon Cross Section Libraries for RCPO1", WAPO-TM-1268, August 1978.

4. R. Gwin and D. W. Magnuson. "The Measurement of Eta and Other Nuclear Properties of U233 and U235 in Critical Aqueous Solutions," Nucl. Sci. Eng., 12, 364 (1962).

5. J. K. Fox, L. W. Gilley, and D. Callihan, "Critical Mass Studies, Part IX, Aqueous U235 Solutions," ORNL-2367, 22 (1958).

6. J. K. Fox, L. W. Gilley, R. Gwin, and J. T. Thomas, "Critical Parameters of Uranium Solutions in Simple Geometry," in Neutron Physics Division Annual Progress Report for Period Ending September 1, 1958, ORNL-2609, Oak Ridge National Laboratory (1958).

7. Rober: $E$. Rothe and Ink: On. Benchmark Cr:tical Experiments on Hign-Enriched Uranyi Nitrate Solution Systems, Nuclear Technology, 41, 207 (1978).

8. J. Hardy, Jr., D. Klein, and J. J. Volpe, "A Study of Physics Parameters in Severa! Water-Moderated Lattices of Slightly Enriched and Natural Uranium," WAPD-TM-931, March 1970.

9. Cross Section Evaluation Working Group Benchmark Specifications, BNL 19302 (ENDF-202), November 1974.

10. J. Hardy, Jr., "Monte Carlo Analyses of TRX Slightly Enriched Uranium-H2O Critical Experiments with ENDF/B-IV and Related Data Sets," WAPD-TM-1307, December 1977.

11. C. R. Weisbin (Editor), "Benchmark Data Testing of ENDF/B-V," BNL-NCS-31531 (ENDF-311), August 1982.

12. R. Sher and S. Fiarman, "Studies of Thermal Reactor Benchmark Data Interpretation: Experimantal Corrections," EPRI NP-209, October 1976. 


\section{Table 1. ENDF/B Material ID's used in the Analyses}

\begin{tabular}{l} 
Nuclide \\
\hdashline U235 \\
U238 \\
U234 \\
U236 \\
H \\
O \\
A1 \\
N \\
F
\end{tabular}

MAT NO.

$\begin{array}{ll}\text { Prel. } & 9228 \\ 1398 & (9237) \\ 1394 & \\ 1396 & \\ 125 & \\ 1276 & (825) \\ 1313 & \\ 1275 & \\ 1309 & \end{array}$

Table 2. Calculated Kcrit Results for Homogeneous Critical Assemblies

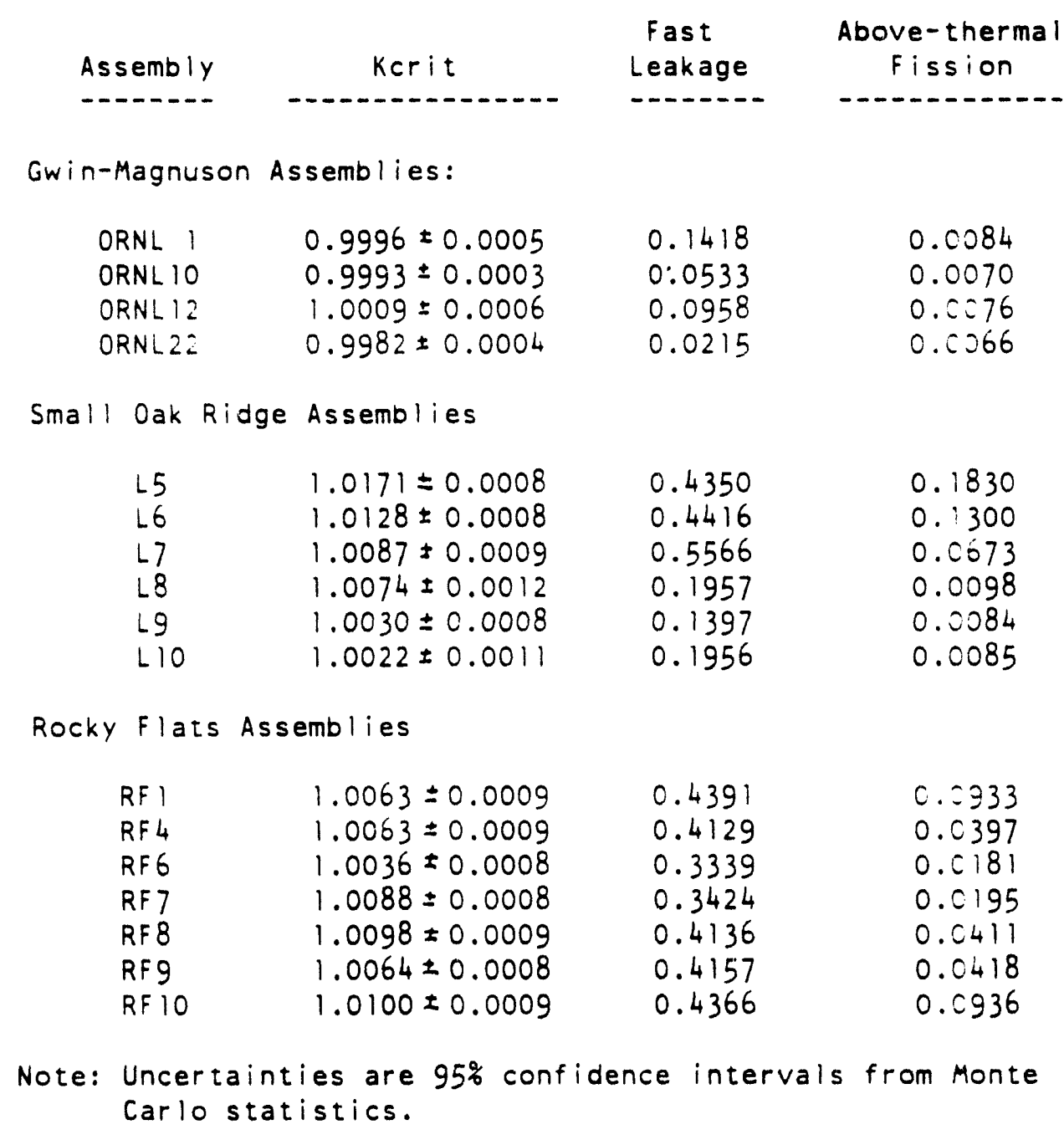


Table 3. Kcrit Sensitivities for Homogeneous Critical Assemblies

$\begin{array}{ll}\text { Case } & \text { Calculated Kerit } \\ \text { Assembly L5: } & \\ \text { Base } & \\ \text { Reduce all atomic number } & 1.0171 \pm 0.0008 \\ \quad \begin{array}{l}\text { densities by } 1 \% \\ \text { Reduce critical height by } 1 \%\end{array} & 1.0078 \pm 0.0014 \\ \text { Reduce N(U235) by } 1 \% & 1.0156 \pm 0.0014 \\ & 1.0168 \pm 0.0019 \\ \text { Assembly L7: } & \\ \text { Base } & 1.0087 \pm 0.0009 \\ \text { Reduce all atomic number } & \\ \text { densities by } 1 \% & 1.0021 \pm 0.0019\end{array}$

Table 4. Lattice Parameters in TRX-1:

Comparison of Measurement and ENDF/B-VI Calculations

$\begin{array}{lcc}\text { Farameter } & \text { Measurement } & \text { Calculation } \\ \text { Rho28 } & 1.320 \pm 0.021 & 1.350 \pm 0.008 \\ \text { Delta25 } & 0.0987 \pm 0.0010 & 0.0992 \pm 0.0009 \\ \text { Delta28 } & 0.0946 \pm 0.0041 & 0.0993 \pm 0.0005 \\ \text { kerit } & 1.0000 \pm 0.0020 & 0.9946 \pm 0.0009\end{array}$

Note: Measured values embody corrections and uncertainties (standard deviations) as evaluated by Sher (Ref. 11). Calculational uncertainties are 95\% confidence intervals reflecting Monte Carlo statistics. 
Figure 1. Homogeneous Benchmark Values of Projected Kcrit versus Above-Thermal Leakage

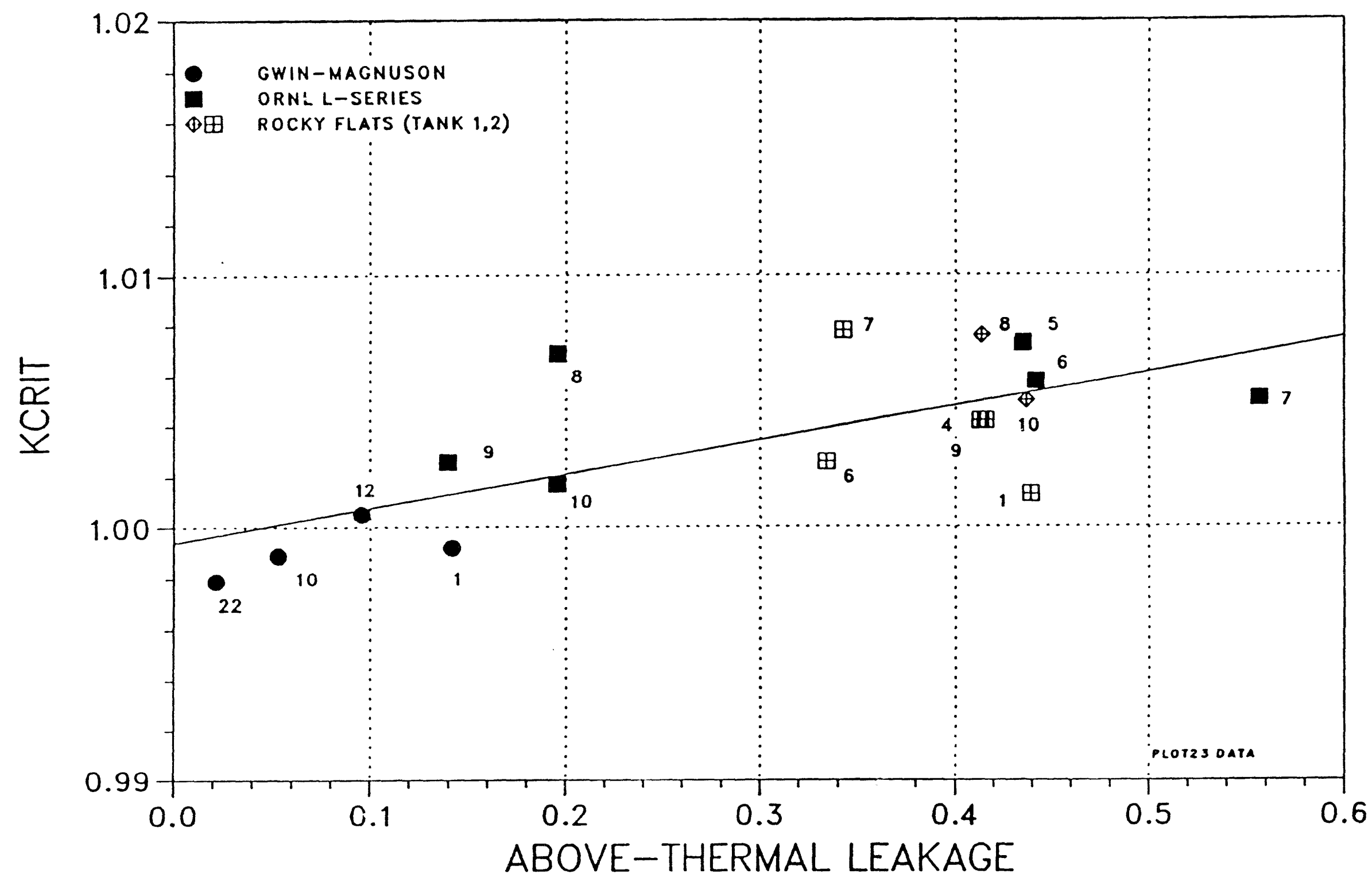


Figure 2. Homogeneous Benchmark Values of Projected Kerit versus Above-Thermal Fission Rate

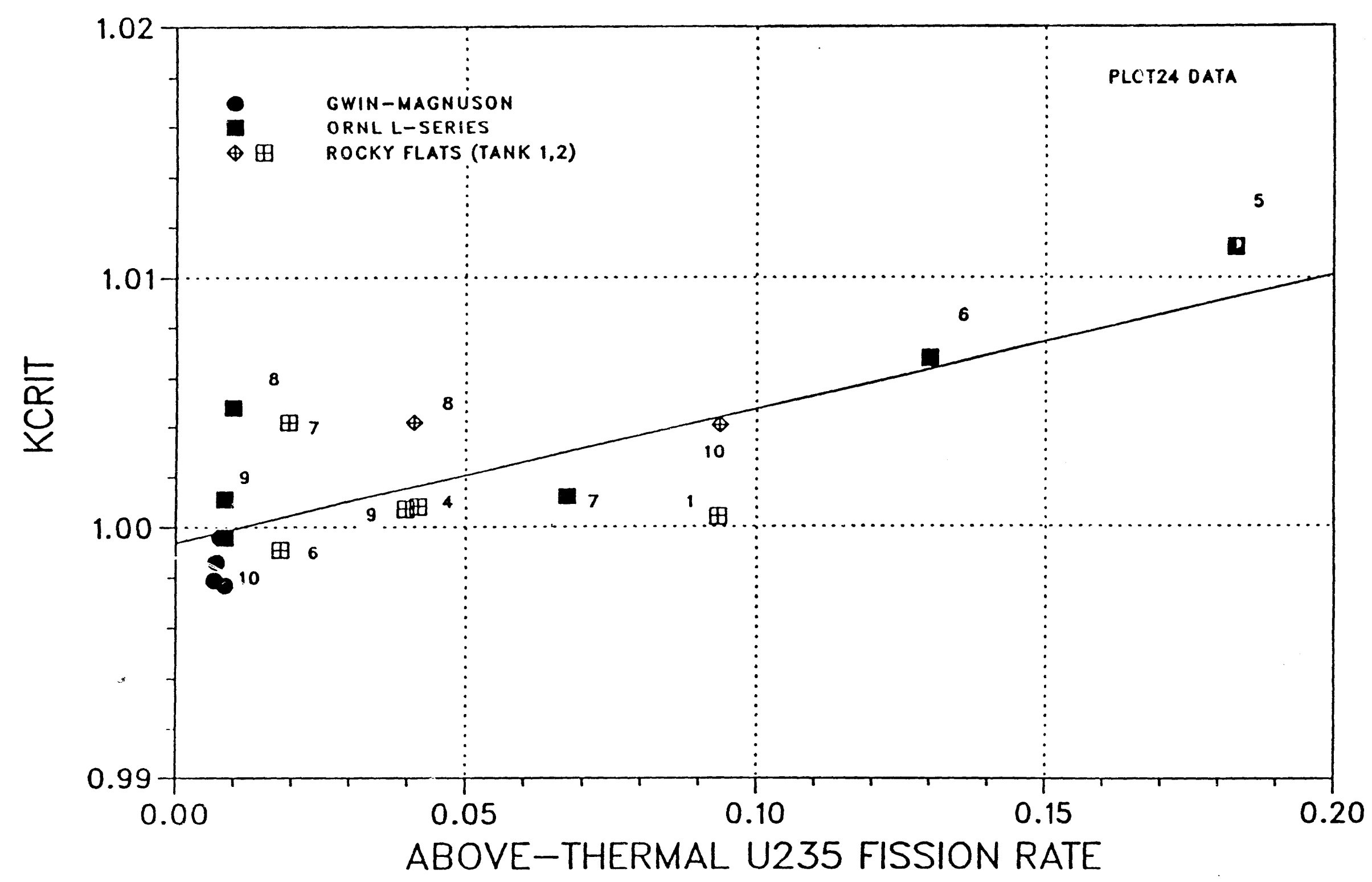


Figure 3. Homogeneous Benchmark Values of Projected Kcrit versus Above-Thermal Fission Rate (Alternative data set with

resonance alpha $=0.512$ )

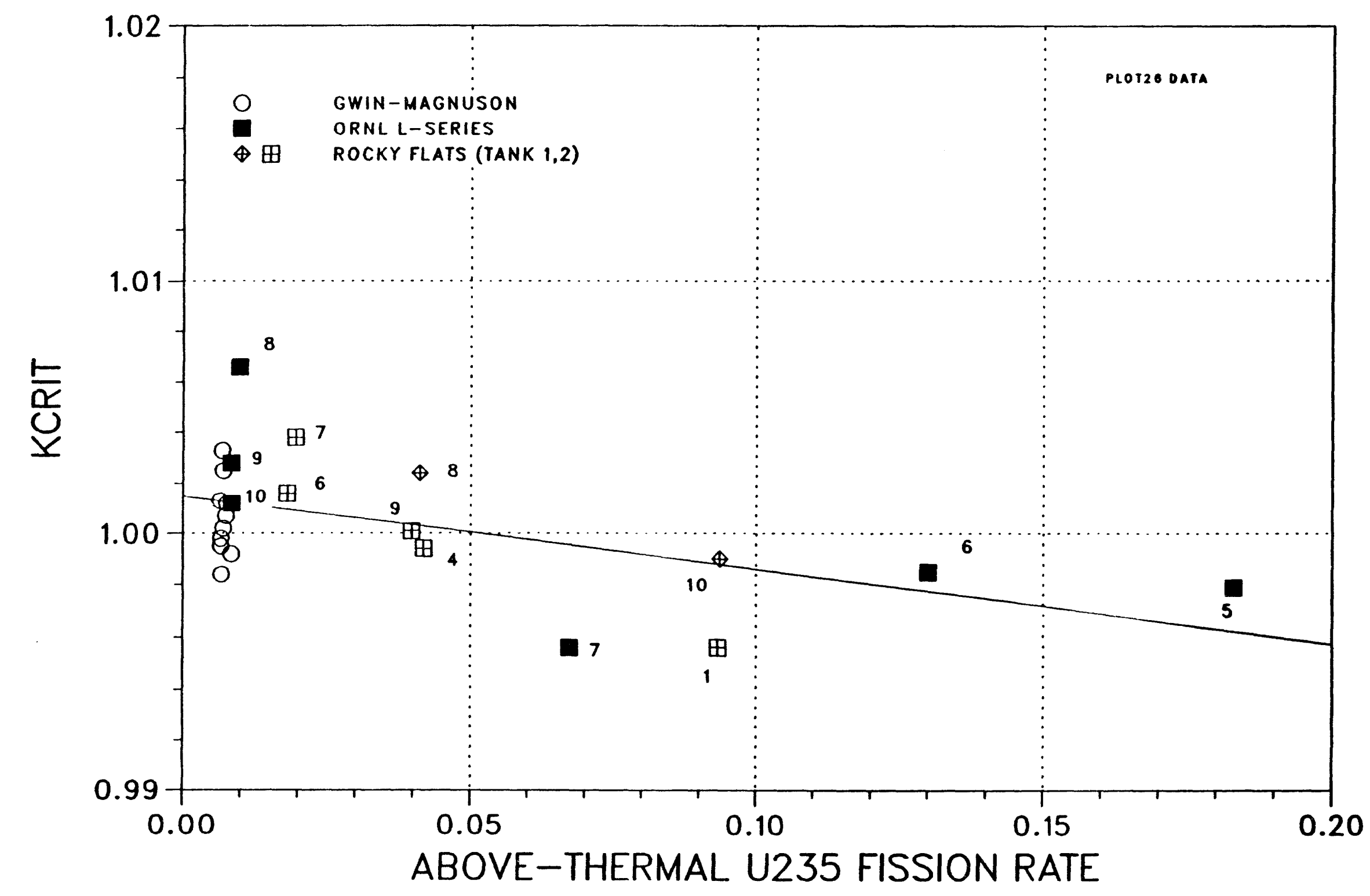


Figure 4. Kcrit vs. Rho 28 for TRX-1

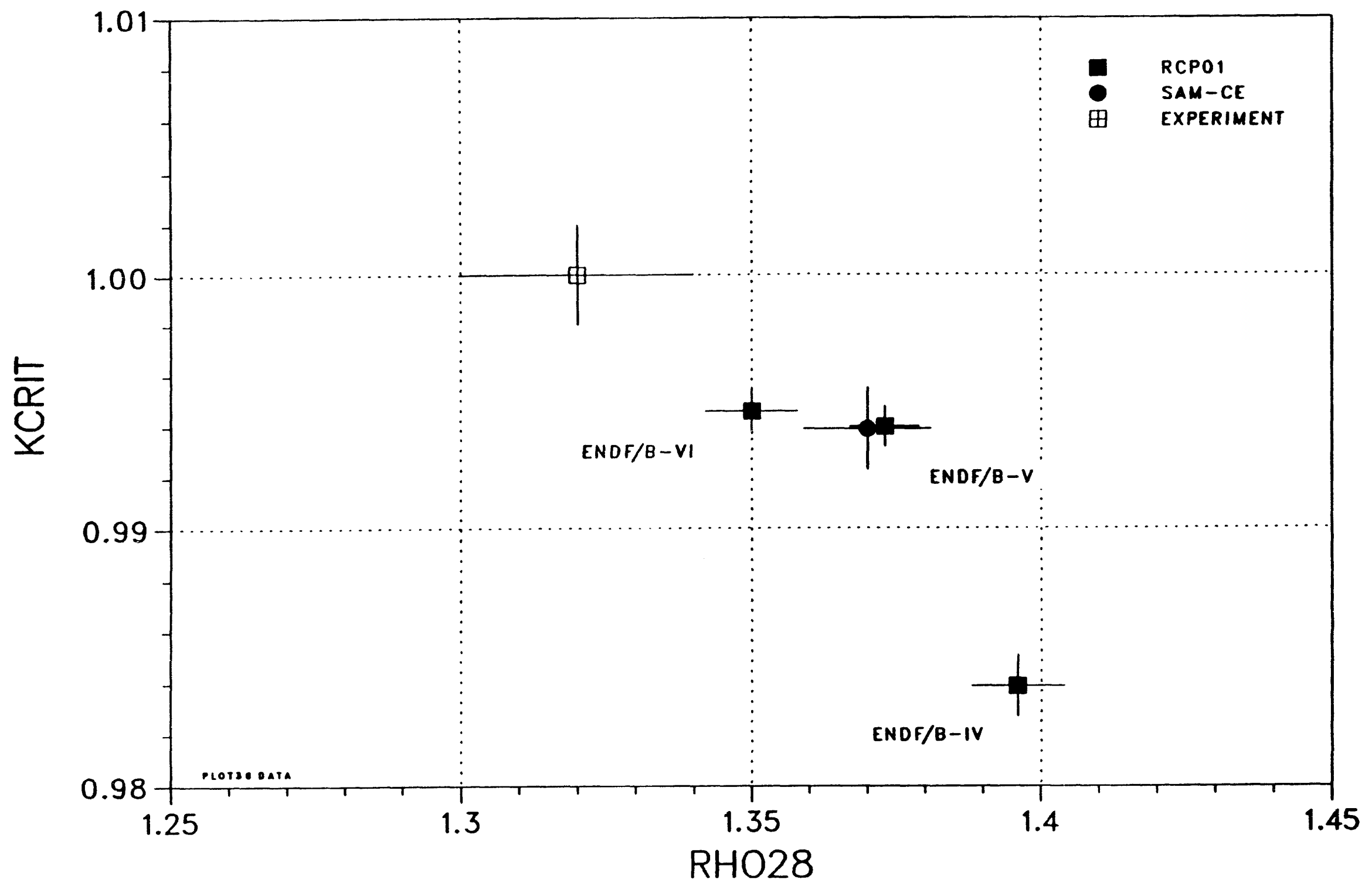



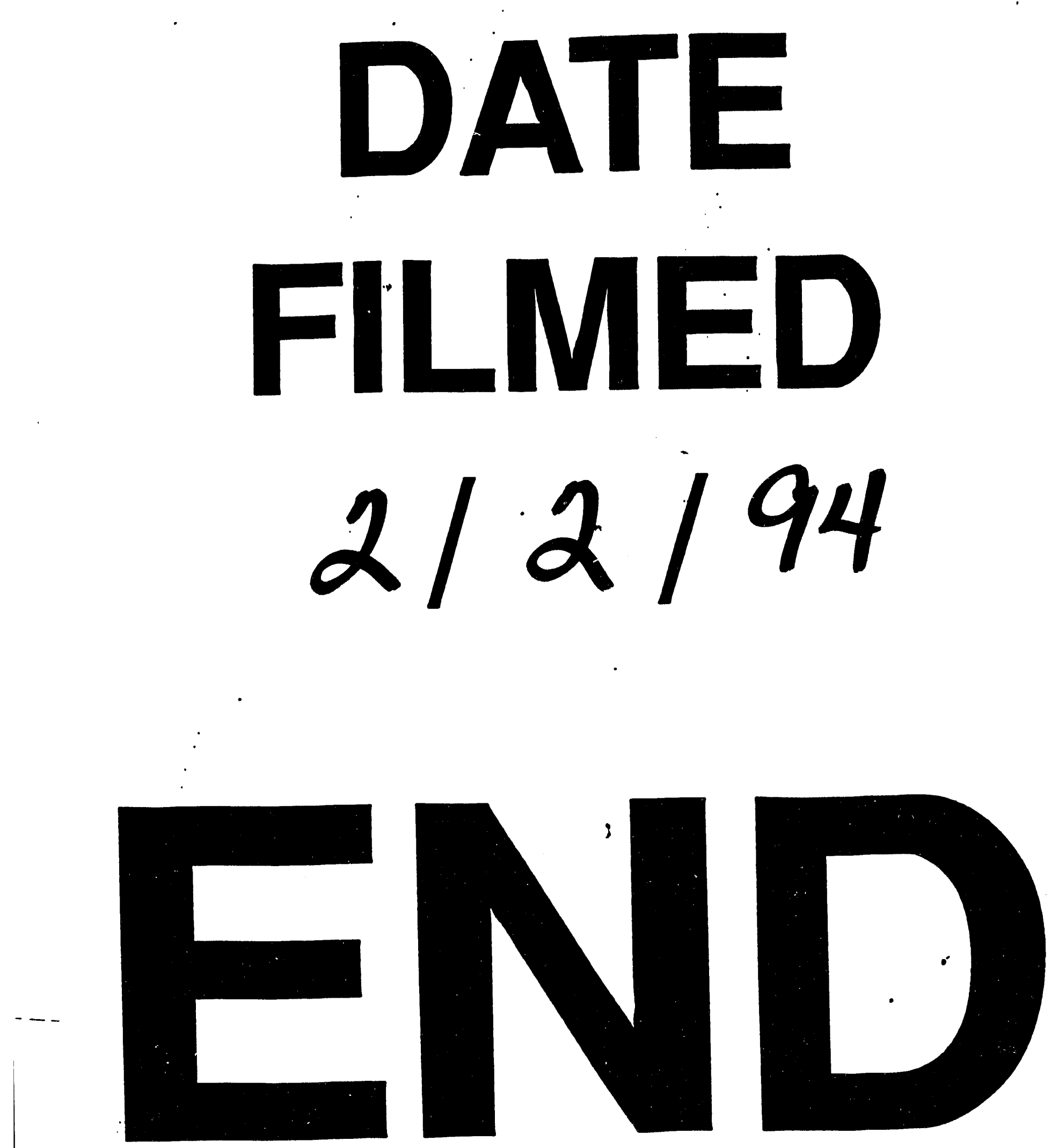
